\title{
COVID-19 Pneumonia in Bilateral Lung Transplant Recipient: Case Report
}

\author{
Juan Pablo Reig Mezquida ${ }^{1 *}$, Alilis Fontana Bellorín², Alberto García Ortega ${ }^{3}$, Gabriel Anguera de Francisco' \\ 'Lung Transplant Unit, Hospital Universitario la Fe, Valencia, Spain \\ 2Department of Thoracic Surgery, Hospital Universitario la Fe, Valencia, Spain \\ ${ }^{3}$ Department of Pulmonology, Hospital Universitario la Fe, Instituto de Investigación Sanitaria "La Fe". Valencia, Spain
}

\section{Article Info}

\section{Article Notes}

Received: May 25, 2019

Accepted: June 19, 2020

\section{*Correspondence:}

Juan Pablo Reig Mezquida, Lung Transplant Unit, Hospital Universitario la Fe, Valencia, Spain; Telephone No: +0034665116403; Email: jpreig@comv.es

\section{(c) 2020 Mezquida JPR. This article is distributed under the} terms of the Creative Commons Attribution 4.0 International License.

\section{Keywords}

Covid-19

Lung Transplantation

Pneumonia

Graft injury

Immunosuppression

\section{Abstract}

The clinical course of Coronavirus disease 2019 (covid-19) in lung transplant recipients remains unknown. We present the fatal clinical course of a 63-year old double lung transplant recipient with severe Covid-19 pneumonia. She had stable graft function before Covid-19 infection. Despite all the supportive care and treatment graft injury progressed, causing patient death. Therefore, the prognosis in lung transplant recipients with Covid-19 infection is not optimistic.

\section{Introduction}

The current pandemic of Coronavirus Disease 2019 (COVID-19) has raised great alarm worldwide, but its impact on transplant patients is unknown, especially in lung transplant recipients. The immunosuppressive maintenance therapy leads to suppose that the course of this disease could be severe ${ }^{1}$. Spain has a National Transplant Organization which coordinates more than 100 lung transplants per year and gives support to transplant patients as atrisk population to COVID-19 infection. We report the fatal clinical course of a lung transplant recipient.

\section{Case report}

On March 31 $1^{\text {st }}, 2020$, a 63-year-old woman, bilateral lung transplant carrier since January 2019, was admitted presenting severe bilateral Covid-19 pneumonia. Her previous lung capacity was normal and she received bilateral lung transplant due to endstage emphysema. On admission, she was in poor general condition, diarrhea, fever, hypoxemia and tachypnea. Her laboratory results showed impaired renal function with creatinine of $2.45 \mathrm{mg} / \mathrm{dL}$, lymphopenia of $0.06 \times 103 / \mu \mathrm{L}$ (5\%), C-reactive protein (CRP) of $110.3 \mathrm{mg} / \mathrm{L}$, Procalcitonin of $1.06 \mathrm{ng} / \mathrm{mL}$, D-dimer of 2,571 ng/ml. At that moment, calcineurin inhibitor was replaced by low dose mTOR inhibitor Everolimus. Methylprednisolone was increased to $1 \mathrm{mg} /$ $\mathrm{kg}$ and meropenem was started. Prophylactic doses of enoxaparin, hydroxychloroquine (200mg daily) and Azithromycin $500 \mathrm{mg} / 24 \mathrm{~h}$ were prescribed. During the first $24 \mathrm{~h}$, the patient clinically improved, but on the third day her laboratory test showed a CRP of $203 \mathrm{mg} / \mathrm{L}$, the interleukin-6 (IL-6) levels increased to $308.9 \mathrm{pg} / \mathrm{mL}$, and D-dimer value raised to $60,479 \mathrm{ng} / \mathrm{ml}$. The CT-scan reported an extensive ground-glass opacities affecting the middle lobe, lingula, and lower lobes, with consolidation areas and small left pleural effusion (Figure 1). 

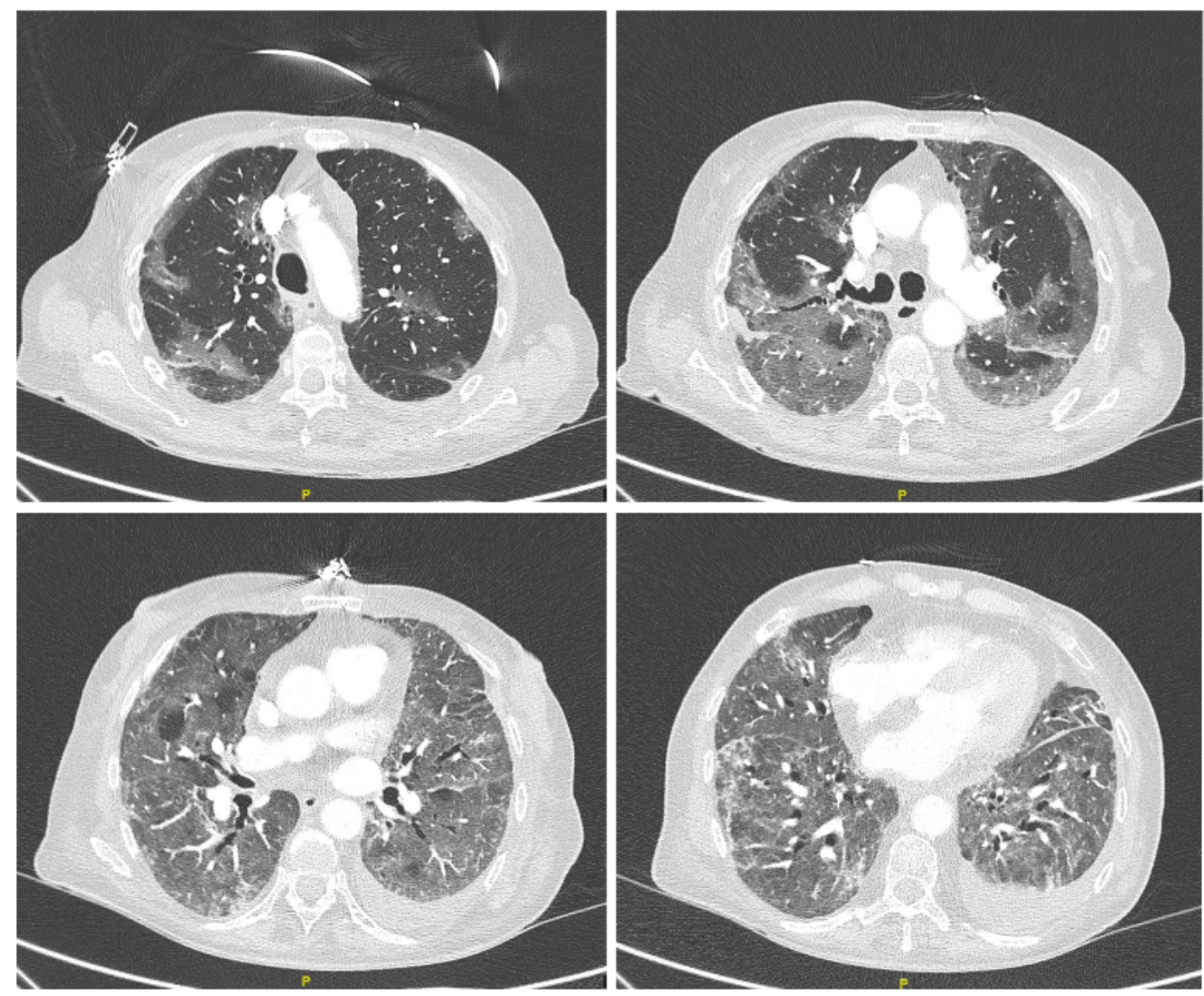

Figure 1: CT-Scan in lung transplant patient with Covid-19 infection. Day 2.

Everolimus blood levels were $1.8 \mathrm{ng} / \mathrm{mL}$. A single dose of anti-IL-6 antibody Tocilizumab was administered (400mg IV) and the patient remained respiratory stable and with sustained diuresis. On day 5 of admission, she developed a clinical deterioration, with p02 of $46 \mathrm{mmHg}$, and was transferred to the Intensive Care Unit (ICU) where high-flow oxygen therapy was started (FiO2 of 100\%, $60 \mathrm{~L} /$ min). At this moment, renal function continued worsening, associated with lower T-cell count, and procalcitonin raised to $9.92 \mathrm{ng} / \mathrm{mL}$. Immunosuppression was discontinued, Caspofungin was started and antibiotic therapy was changed to piperacillin-tazobactam. On day 7 mechanical ventilation was required due to physical exhaustion and lactate elevation. The renal function continued worsening and transaminases raised ten times normal values. Lymphopenia continued at values $0.08 \times 103 / \mu \mathrm{L}(7 \%)$. Aspergillus niger was isolated from bronchial sample. Despite the support measures, the patient eventually died 9 days after admission due to multi-organ failure.

\section{Discussion}

The T-cell immune response to Covid-19 in lung transplant recipients remains unknown. It is expected to be suppressed due to the maintenance of immunosuppressive therapy usually with three drugs ${ }^{2}$. Some renal transplant recipients from China were described with good outcome ${ }^{3}$, and data from a single center experience in liver transplant recipients, suggested also similar outcomes to general population ${ }^{4}$. Recent data of solid organ recipients and Covid-19 infection have been published from a singlecenter, reporting a mortality rate of $27.8 \%{ }^{5}$. Following the recommendations, immunosuppressive therapy was reduced to minimum dose and treated with Hydroxychloriquine, which has been proposed as a therapeutic option with promising results 6 . The change to mTOR inhibitor is performed in lung transplant patients with secondary renal impairment ${ }^{7}$, which has a depletive effect on interleukin IL-2R. IL2 overexpression has been also described in the cytokine release syndrome of severe Covid-19 pneumonia ${ }^{8}$, but the role mTOR inhibitors in Covid-19 remains unclear. The detection of Aspergillus in bronchial sample could be a secondary infection, first described in $30 \%$ of Covid-19 patients who required admission to the ICU ${ }^{1}$. The rapid course of infection in the patient we present, suggests that the outcome in lungtransplant population might be very poor. Triple therapy as maintenance immunosuppression, anatomical changes of the graft after transplant, and the lung as the targetorgan of Sars-CoV2, could justify the worse clinical course of lung transplant recipients after Covid-19 pneumonia. 
Future pathological studies will be useful to clarify the differences between lung transplant recipients and immunocompromised patients.

\section{Acknowledgement}

Dr. Reig Mezquida, Dr. García Ortega and Dr. Anguera de Francisco treated the patient during hospitalization and contributed to the creation of the manuscript. Dr. Fontana Bellorín contributed to the creation and translation of the manuscript.

\section{References}

1. Huang C, Wang X, Li L, et al. Clinical features of patients infected with 2019 novel coronavirus in Wuhan, China. Lancet. 2020 Feb; 15: 497 506.

2. Scheffert JL, Raza K. Immunosuppression in lung Transplantation. Journal Thorac Dis. 2014 Aug; 6(8): 1039-53.
3. Arpali E, Akyollu B, Yelken B, et al. Case Report: A kidney Transplant Patient with Mild COVID-19. Transplant infectious disease. 2020 Apr [Epub ahead of print].

4. D'Antiga L. Coronaviruses and immunosuppressed patients. The facts during the third epidemic. Liver Transplantation. 2020 Mar [Epub ahead of print].

5. Fernández-Ruiz M, Andrés A, Loinaz C, et al. COVID-19 in solid organ transplant recipients: a single-center cases series from Spain. American J of Transplantation. 2020 Apr [Epub ahead of print].

6. Sarma P, Kaur H, Kumar H, et al. Virological and Clinical Cure in Covid-19 Patients Treated with Hydroxychloroquine: A Systematic Review and Meta-Analysis. Journal of Medical Virology. 2020 Apr [Epub ahead of print].

7. Fine N, Sudhir K. Recent advances in Mammalian Target of Rapamycin Inhibitor Use in Heart and Lung Transplantation. Transplantation. 2016 Dec; 100(12): 2558-68.

8. Chen G, Wu D, Guo W, et al. Clinica and immunological features of severe and moderate coronavirus disease 2019. The Journal olf Clinical investigation. 2020 Mar. [Epub ahead of print]. 